ARTICLE

Received 13 Feb 2016 | Accepted 24 Jun 2016 | Published 19 Aug $2016 \quad$ DOI: 10.1038/ncomms12371

\title{
Microfibres and macroscopic films from the coordination-driven hierarchical self-assembly of cylindrical micelles
}

\author{
David J. Lunn', Oliver E.C. Gould ${ }^{1}$, George R. Whittell ${ }^{1}$, Daniel P. Armstrong ${ }^{2}$, Kenneth P. Mineart²,
} Mitchell A. Winnik ${ }^{3}$, Richard J. Spontak ${ }^{2,4}$, Paul G. Pringle ${ }^{1} \&$ lan Manners $^{1}$

Anisotropic nanoparticles prepared from block copolymers are of growing importance as building blocks for the creation of synthetic hierarchical materials. However, the assembly of these structural units is generally limited to the use of amphiphilic interactions. Here we report a simple, reversible coordination-driven hierarchical self-assembly strategy for the preparation of micron-scale fibres and macroscopic films based on monodisperse cylindrical block copolymer micelles. Coordination of $\mathrm{Pd}(\mathrm{O})$ metal centres to phosphine ligands immobilized within the soluble coronas of block copolymer micelles is found to induce intermicelle crosslinking, affording stable linear fibres comprised of micelle subunits in a staggered arrangement. The mean length of the fibres can be varied by altering the micelle concentration, reaction stoichiometry or aspect ratio of the micelle building blocks. Furthermore, the fibres aggregate on drying to form robust, self-supporting macroscopic micelle-based thin films with useful mechanical properties that are analogous to crosslinked polymer networks, but on a longer length scale.

\footnotetext{
${ }^{1}$ School of Chemistry, University of Bristol, Bristol BS8 1TS, UK. ${ }^{2}$ Department of Chemical and Biomolecular Engineering, North Carolina State University, Raleigh, North Carolina 27695, USA. ${ }^{3}$ Department of Chemistry, University of Toronto, Toronto, Ontario, Canada M5S 3H6. ${ }^{4}$ Department of Materials Science and Engineering, North Carolina State University, Raleigh, North Carolina 27695, USA. Correspondence and requests for materials should be addressed to P.G.P. (email: paul.pringle@bristol.ac.uk) or to I.M. (email: ian.manners@bristol.ac.uk).
} 
$\mathrm{N}$ ature is replete with examples of the bottom-up preparation of functional materials that display hierarchical order ${ }^{1-4}$. Metal coordination plays a vital role in many of these biological systems. For example, mammalian bone is reinforced by the reversible crosslinking of anisotropic collagen fibres with calcium ions ${ }^{5}$, and marine mussels derive their underwater adhesion and self-healing properties from the iron-mediated crosslinking of catechol groups ${ }^{6,7}$. Such metal-ligand interactions can be reversible and dynamic, with a wide range of bond strengths and labilities dependent on the choice of metal, ligand and coordination mode. In synthetic materials, metal coordination chemistry has been used for the preparation of a variety of supramolecular and covalent polymers ${ }^{8-14}$, dendrimers ${ }^{15,16}$, macrocycles ${ }^{17,18}$, gels ${ }^{19-22}$, metal-organic frameworks ${ }^{23,24}$ and protein assemblies ${ }^{25,26}$. However, the use of metal-ligand interactions is much less explored in the area of colloidal self-assembly. Metal coordination has been used to prepare hybrid magnetite/polystyrene nanoparticle chains through interparticle crosslinking after prior alignment of nanoparticles using an external magnetic field ${ }^{27}$. In addition, the coordinationdriven self-assembly of colloidal particles has been described where immobilized palladium centres and pyridyl ligands were used to direct the interparticle linking of adjacent 'patchy' polystyrene particles ${ }^{28}$.

The use of anisotropic building blocks is increasingly recognized as a key requirement for the realization of well-defined hierarchical structures $^{29,30}$. Block copolymer (BCP) solution self-assembly is an elegant strategy by which such anisotropic subunits can be conveniently prepared in the form of colloidal, core-shell nanoparticles ${ }^{31-35}$. For example, BCP micelles bearing surface patches of segregated chemical functionality have been used as building blocks for precise hierarchical self-assembly under kinetic control to prepare complex mesostructures ${ }^{36,37}$. Furthermore, living crystallization-driven self-assembly (CDSA) of BCPs with a crystallizable core-forming block can be used to prepare monodisperse cylindrical micelles with controlled lengths and block co-micelles with compartmentalized chemical functionality ${ }^{38-41}$. On addition of a selective solvent, amphiphilic block co-micelle building blocks form 'supermicelles', with structures ranging from micrometre-sized spherical or cylindrical assemblies to continuous one-dimensional or three-dimensional (3D) superlattices ${ }^{42-44}$. Cylindrical micelles have also been assembled end to end by the addition of further homopolymer with the same composition as the core-forming block. This additional homopolymer functions as a 'glue' between micelle subunits, affording short, polydisperse, linear and branched chains of micelles ${ }^{45}$.

Despite these advances, methods for the self-assembly of anisotropic BCP nanoparticles are generally limited to the exploitation of building-block amphiphilicity ${ }^{46}$. Approaches that utilize alternative interactions are anticipated to diversify both the structures and properties of the resulting hierarchical materials, but very few examples have been reported thus far. Multiblock assemblies have been prepared by the covalent head-to-tail linking of BCP nanotubes, where coupling was achieved using carboxyl and amino groups that protruded from the termini of the precursors ${ }^{47}$. This approach has also been extended to prepare composite 'nanoropes' by wrapping amino-containing nanocylinders around carboxyl-containing nanofibres, where the functionality was localized within the BCP micelle coronas ${ }^{48}$. Herein we demonstrate the reversible coordination-driven hierarchical self-assembly of monodisperse cylindrical BCP micelles, affording a series of complex superstructures and stable linear fibres that can be further processed into macroscopic micelle-based thin films.

\section{Results}

Preparation of monodisperse phosphine-containing BCP micelles. The BCP poly(ferrocenyldimethylsilane) $)_{60}-b$-poly (methylvinylsiloxane $)_{574} \quad\left(\mathrm{PFS}_{60}-b\right.$ - $\left.\mathrm{PMVS}_{574}\right)$, containing vinyl groups suitable for the incorporation of pendant functional groups, was prepared by sequential living anionic polymerization. Radical hydrophosphination under photolytic conditions was used to functionalize a percentage of the vinyl groups with diphenylphosphine, affording $\mathbf{B C P}^{\mathbf{P}}$ (Fig. 1, Supplementary Fig. 1 and Supplementary Table 1) with $35 \%-\mathrm{PPh}_{2}$ incorporation based on analysis by proton nuclear magnetic resonance $\left({ }^{1} \mathrm{H}\right.$ NMR) spectroscopy. Monodisperse cylindrical micelles were prepared from $\mathbf{B C P}^{\mathbf{P}}$ by living CDSA utilizing the crystalline nature of the PFS core-forming block ${ }^{38-41}$. First, polydisperse cylindrical micelles were prepared by the homogeneous nucleation of $\mathbf{B C P}^{\mathbf{P}}$ in EtOAc, a selective solvent for the polysiloxane block (Supplementary Fig. 2). The resulting micelles were then sonicated to yield short seed micelles $\left(L_{\mathrm{n}}=37 \mathrm{~nm}, L_{\mathrm{w}} / L_{\mathrm{n}}=1.16\right.$, Supplementary Fig. 3) suitable for the initiation of living CDSA. Monodisperse BCPP $\mathbf{P}^{\mathbf{P}}$ micelles $\left(\mathbf{M}_{545}: L_{\mathrm{n}}=545 \mathrm{~nm}, L_{\mathrm{w}} / L_{\mathrm{n}}=1.05\right)$ were subsequently prepared by the living CDSA of a known amount of $\mathbf{B C P}^{\mathbf{P}}$ unimer (molecularly dissolved BCP in a good solvent for both blocks) from the termini of the seed micelles. By changing the unimer-to-seed ratio, the lengths and therefore aspect ratios of the resulting micelles could be precisely controlled to prepare a variety of suitable micelle-building blocks (Supplementary Fig. 4 and Supplementary Table 2).

Coordination-driven hierarchical self-assembly. Complexation of the phosphine ligands embedded in the micelle corona by $\mathrm{Pd}(\mathrm{II})$ centres was explored by the addition of varying amounts of $\mathrm{Pd}(\mathrm{OAc})_{2}$ to solutions of $\mathbf{M}_{\mathbf{5 4 5}}$ in EtOAc. Transmission electron microscopy (TEM), energy dispersive X-ray spectroscopy (EDX) and ${ }^{31} \mathrm{P}$ NMR spectroscopy confirmed the metal coordination and structural integrity of the cylindrical micelles (Supplementary Figs 5 and 6). After metal complexation, the resulting BCP

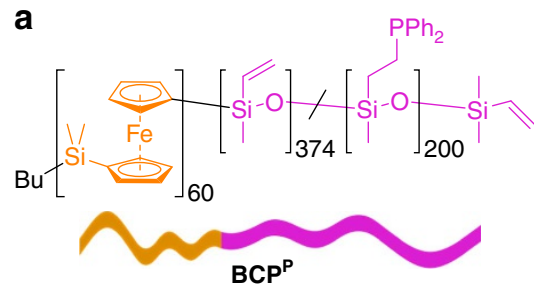

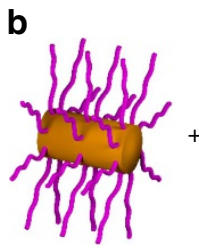

Seed micelle

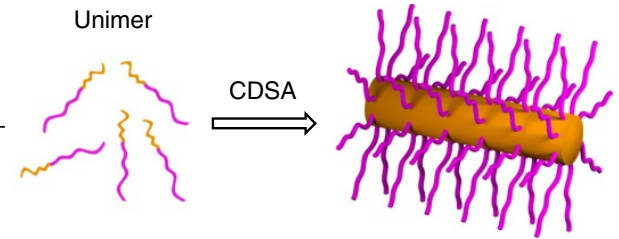

Monodisperse micelle

Figure 1 | Preparation of monodisperse $\mathbf{B C P} \mathbf{P}^{\mathbf{P}}$ micelles. Schematic depiction of (a) $\mathbf{B C P} \mathbf{P}$ and (b) the living CDSA of $\mathbf{B C P} \mathbf{P}^{\mathbf{P}}$ in a selective solvent to afford monodisperse cylindrical micelles with a crystalline PFS core (orange) and a phosphine-functionalized polysiloxane corona (pink). The micelle illustrations in this figure are of idealized structures. The polysiloxane corona presumably overhangs at the core termini to provide some 'dynamic' coverage of the crystal face. 
cylinders could be dispersed in a good solvent for both blocks (for example, tetrahydrofuran (THF)) without dissolution, consistent with intramicellar coronal crosslinking (Supplementary Figs 7 and 8). Presumably, the immobilized monodentate phosphine ligands or vinyl groups from neighbouring polymer chains within the micelle coronas coordinate to the same $\mathrm{Pd}(\mathrm{II})$ metal centre.

We also investigated the complexation of $\operatorname{Pd}(0)$ centres by adding 0.5 equiv. $\operatorname{Pd}(0)$ as $\operatorname{Pd}_{2}(\mathrm{dba})_{3}(\mathrm{dba}$, dibenzylideneacetone) to a solution of $\mathbf{M}_{545}$ in EtOAc. In contrast, aggregation of the cylindrical micelles in this case afforded long linear fibres of connected cylindrical micelles, as observed by TEM analysis after solvent evaporation (Fig. 2). This was consistent with considerable inter-, rather than solely intra-, micellar coordination. The resulting structures were analysed by EDX and ${ }^{31} \mathrm{P}$ NMR spectroscopy (Supplementary Figs 5 and 9). To confirm that the linear fibres observed were not simply the result of a drying effect during TEM sample preparation, the solutions were likewise examined by dynamic light scattering (DLS) before solvent evaporation (Supplementary Fig. 10). This indicated the formation of much larger aggregates in solution in the case of the addition of $\operatorname{Pd}(0)$ centres, whereas no significant change in hydrodynamic size was detected when Pd(II) was added, consistent with intramicellar coordination in the latter case.

When the solution of the $\operatorname{Pd}(0)$ species $\operatorname{Pd}_{2}(\mathrm{dba})_{3}$ was added to a solution of $\mathbf{B C P} \mathbf{P}^{\mathbf{P}}$ micelles in EtOAc, the initial red colour faded over several minutes, presumably as the immobilized phosphines within the micelle coronas displaced the coordinated dba ligands. The resulting fibres formed by micelle aggregation remained colloidally stable and the solution could be diluted with negligible change in their length. However, the addition of a more strongly coordinating phosphine could be used to remove the intermicelle crosslinks and disassemble the linear fibres into their constituent micelle subunits. For example, when an excess of the chelating phosphine 1,2-bis(diphenylphosphino)ethane (dppe) was added to a solution of linear fibres at ambient temperature, the solution became yellow, consistent with the formation of $\operatorname{Pd}(\text { dppe })_{2}$, as confirmed by ${ }^{31} \mathrm{P}$ NMR spectroscopy. Subsequent TEM analysis in this case revealed the regeneration of discrete, non-aggregated cylindrical micelles, confirming the reversibility of the coordination-driven self-assembly (Supplementary Fig. 12).

The divergent behaviour of the $\mathbf{B C P}^{\mathbf{P}}$ cylindrical micelles on addition of $\operatorname{Pd}(\mathrm{II})$ and $\operatorname{Pd}(0)$ centres presumably reflects the different coordination preferences for the metal centres in these two oxidation states. The coronas of $\mathbf{B C P}^{\mathbf{P}}$ cylindrical micelles represent an unusual and complex coordination environment for both metal centres. Intramicelle crosslinking is anticipated to occur if a metal centre coordinated to a phosphine ligand on one polymer forms a bond with a phosphine located in close proximity on a neighbouring polymer chain (Supplementary Figs 7 and 13). In the corona of a micelle, the main coordination scenarios for $\mathrm{Pd}(\mathrm{OAc})_{2}$ would be expected to be $\mathrm{Pd}\left(\mathrm{L}_{1}\right)$ $\left(-\mathrm{PPh}_{2}\right)(\mathrm{OAc})_{2}$ and $\mathrm{Pd}\left(-\mathrm{PPh}_{2}\right)_{2}(\mathrm{OAc})_{2}$ (ref. 49), where $\mathrm{L}_{1}$ would most likely correspond to free vinyl groups along the polymer chain (Supplementary Figs 14 and 15) or bridging acetate ligands. In contrast, the complexes resulting from the addition of $\operatorname{Pd}_{2}(\mathrm{dba})_{3}$ are expected to consist of $\mathrm{Pd}(\mathrm{dba})\left(-\mathrm{PPh}_{2}\right)_{2}$ in dynamic equilibrium with $\mathrm{Pd}\left(\right.$ vinyl) $\left(-\mathrm{PPh}_{2}\right)_{2}$ and $\mathrm{Pd}\left(-\mathrm{PPh}_{2}\right)_{3}$ environments, the latter involving three phosphine ligands $s^{50}$. As the micelle corona possesses a phosphine loading of only 35\%, there may be, on average, only two readily available phosphines for the coordination sphere of each metal centre. In the case of the $\mathrm{Pd}(\mathrm{II})$ species $\mathrm{Pd}(\mathrm{OAc})_{2}$, this would result in intramicelle crosslinking. However, for the $\mathrm{Pd}(0)$ precursor $\mathrm{Pd}_{2}(\mathrm{dba})_{3}$, metal

a
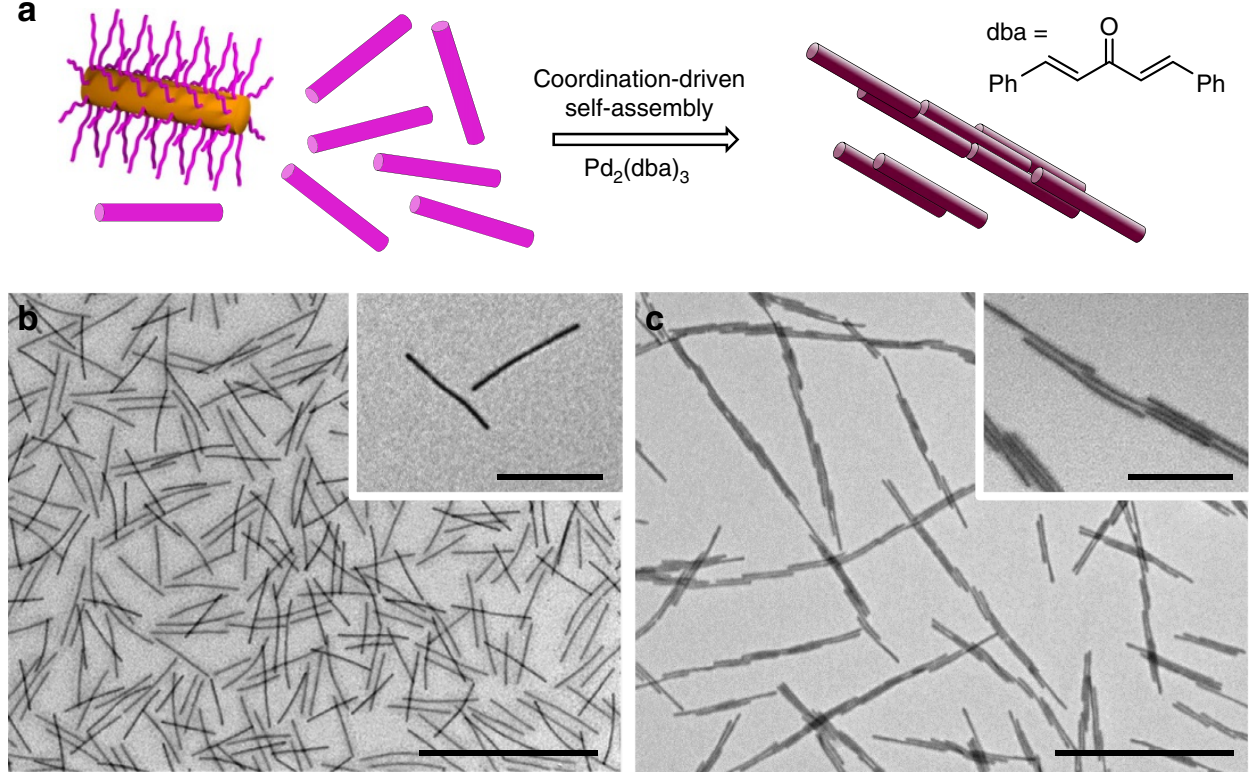

d

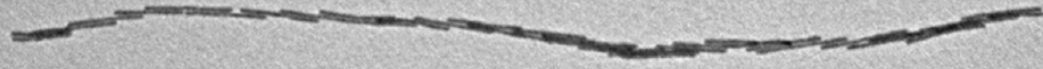

Figure 2 | Coordination-driven hierarchical self-assembly of cylindrical BCP micelles. (a) Schematic depiction of the coordination-driven self-assembly of $\mathbf{B C P} \mathbf{P}^{\mathbf{P}}$ micelles on addition of $\mathrm{Pd}_{\mathbf{2}}(\mathrm{dba})_{3}$. Pink and purple blocks correspond to $\mathbf{B C P} \mathbf{P}^{\mathbf{P}}$ and $\mathbf{P d}$-coordinated $\mathbf{B C} \mathbf{P}^{\mathbf{P}}$, respectively. TEM images of $\mathbf{M}_{\mathbf{5 4 5}}$ $\left(0.5 \mathrm{mg} \mathrm{ml}^{-1}\right)$ before $\mathrm{Pd}_{2}(\mathrm{dba})_{3}$ addition (b), linear fibres of $\mathbf{M}_{\mathbf{5 4 5}}\left(0.5 \mathrm{mg} \mathrm{ml}^{-1}\right)$ after $\mathrm{Pd}_{2}(\mathrm{dba})_{3}$ addition (c) and $>10 \mu \mathrm{m}$ linear fibre of $\mathbf{M}_{\mathbf{5 4 5}}$ after $\mathrm{Pd}_{2}(\mathrm{dba})_{3}$ addition and further dilution with EtOAc (d) (see Supplementary Fig. 11 for a lower-magnification image). Scale bars correspond to 2,000 nm in main images and $500 \mathrm{~nm}$ in insets. 
centres at the periphery of micelle coronas would be available to take advantage of intermicelle collisions, thereby forming complexes with more than two phosphine ligands and causing intermicellar crosslinking.

Fibre length variation using coordination-driven hierarchical self-assembly. The concentration of $\mathbf{B C P}^{\mathbf{P}}$ micelles was observed to have a significant influence on the degree of aggregation and length of linear fibres obtained by coordination-driven selfassembly (Fig. 3a). At a lower concentration of $1 \mathrm{mg} \mathrm{ml}^{-1}, 24 \mathrm{~h}$ after $\mathrm{Pd}_{2}(\mathrm{dba})_{3}$ addition, $99 \%$ of the micelles were involved in coordination-driven self-assembly. As the micelle concentration was decreased, the percentage of micelle subunits that coordinated to form linear fibres decreased until negligible self-assembly was observed below a concentration of $0.05 \mathrm{mg} \mathrm{ml}^{-1}$ (Fig. 3b). At these very low micelle concentrations, predominantly intrarather than intermicelle crosslinking occurs, as evidenced by the stability of the BCP cylinders when dispersed in a good solvent for both blocks (Supplementary Fig. 13). These dilute micelle solutions remained stable indefinitely after the addition of $\operatorname{Pd}(0)$ with negligible change in the number micelles involved in intermicelle crosslinking. Notably, longer fibres were only obtained at higher concentrations when more of the micelles were involved in intermicelle crosslinking. At micelle concentrations $>1 \mathrm{mg} \mathrm{ml}^{-1}$ some precipitation of the larger fibre-like micelle aggregates was observed. Moreover, when solutions of $\mathbf{B C P}^{\mathbf{P}}$ micelles were stirred immediately after the addition of $\operatorname{Pd}(0)$ to increase the number of micelle collisions, almost complete aggregation and precipitation of the micelles occurred. In a control experiment, $\mathrm{Pd}_{2}(\mathrm{dba})_{3}$ was added to solutions of nonphosphine-containing micelles (Supplementary Figs 16 and 17) and no coordination-driven self-assembly was observed over the time periods required for the controlled aggregation of $\mathbf{B C P}^{\mathbf{P}}$ containing micelles.
To quantify the effect of stoichiometry on coordination-driven self-assembly, different amounts of a $\operatorname{Pd}_{2}(\mathrm{dba})_{3}$ stock solution (0.1-1 equiv. $\operatorname{Pd}(0)$ with respect to immobilized phosphine) were added to solutions of $\mathbf{M}_{545}\left(0.5 \mathrm{mg} \mathrm{ml}^{-1}\right)$ in EtOAc. On the basis of our initial experiments, a micelle concentration of $0.5 \mathrm{mg} \mathrm{ml}^{-1}$ was chosen at which ca. $92 \%$ of the micelles participate in coordination-driven self-assembly (Fig. 3a), resulting in fibres that are sufficiently long to be readily detected, but not so long as to make accurate analysis by TEM difficult (where fibres span several grid squares). Statistical analysis of TEM images obtained from samples drop-cast after $24 \mathrm{~h}$ (Supplementary Fig. 18 and Supplementary Table 3) revealed a trend between the mean length $\left(L_{\mathrm{n}}\right)$ of the coordination structures and the $\operatorname{Pd}(0)$ : phosphine ratio (Fig. 3d). The maximum mean length of the linear fibres was achieved on addition of 0.4 equiv. of $\operatorname{Pd}(0)$ : $L_{\mathrm{n}}=2,470 \mathrm{~nm}, L_{\mathrm{w}} / L_{\mathrm{n}}=1.18$ (Fig. $3 \mathrm{e}$ ).

To investigate the influence of micelle length on coordinationdriven self-assembly, longer cylindrical $\mathbf{B C} \mathbf{P}^{\mathbf{P}}$ micelles $\left(\mathbf{M}_{\mathbf{9 7 0}}\right.$ : $\left.L_{\mathrm{n}}=970 \mathrm{~nm}, L_{\mathrm{w}} / L_{\mathrm{n}}=1.04\right)$ were prepared. Different amounts of a $\mathrm{Pd}_{2}(\mathrm{dba})_{3}$ stock solution $(0.1-1$ equiv. $\mathrm{Pd}(0)$ with respect to immobilized phosphine) were then added to solutions of $\mathbf{M}_{\mathbf{9 7 0}}$ $\left(0.5 \mathrm{mg} \mathrm{ml}^{-1}\right)$ in EtOAc and the solutions similarly aged for $24 \mathrm{~h}$. Statistical analysis of TEM images indicated an analogous trend to that observed with the shorter $\mathbf{M}_{\mathbf{5 4 5}}$ micelles (Fig. 3d) although, as expected, larger mean lengths were observed due to the increased length of the micelle-building blocks (Supplementary Fig. 19 and Supplementary Table 3). Once again a maximum mean length was obtained when 0.4 equiv. of $\operatorname{Pd}(0)$ was added: $L_{\mathrm{n}}=4,030 \mathrm{~nm}$, $L_{\mathrm{w}} / L_{\mathrm{n}}=1.24$ (Fig. 3f). When more than 1 equiv. of $\operatorname{Pd}(0)$ was added to solutions of either $\mathbf{M}_{\mathbf{5 4 5}}$ or $\mathbf{M}_{\mathbf{9 7 0}}$, both side-to-side and end-to-end aggregation were detected, which led to the precipitation of a large number of the fibres (Supplementary Fig. 20).

The overall dimensions of the resulting fibres are presumably governed by a complex process that involves competing intra- and
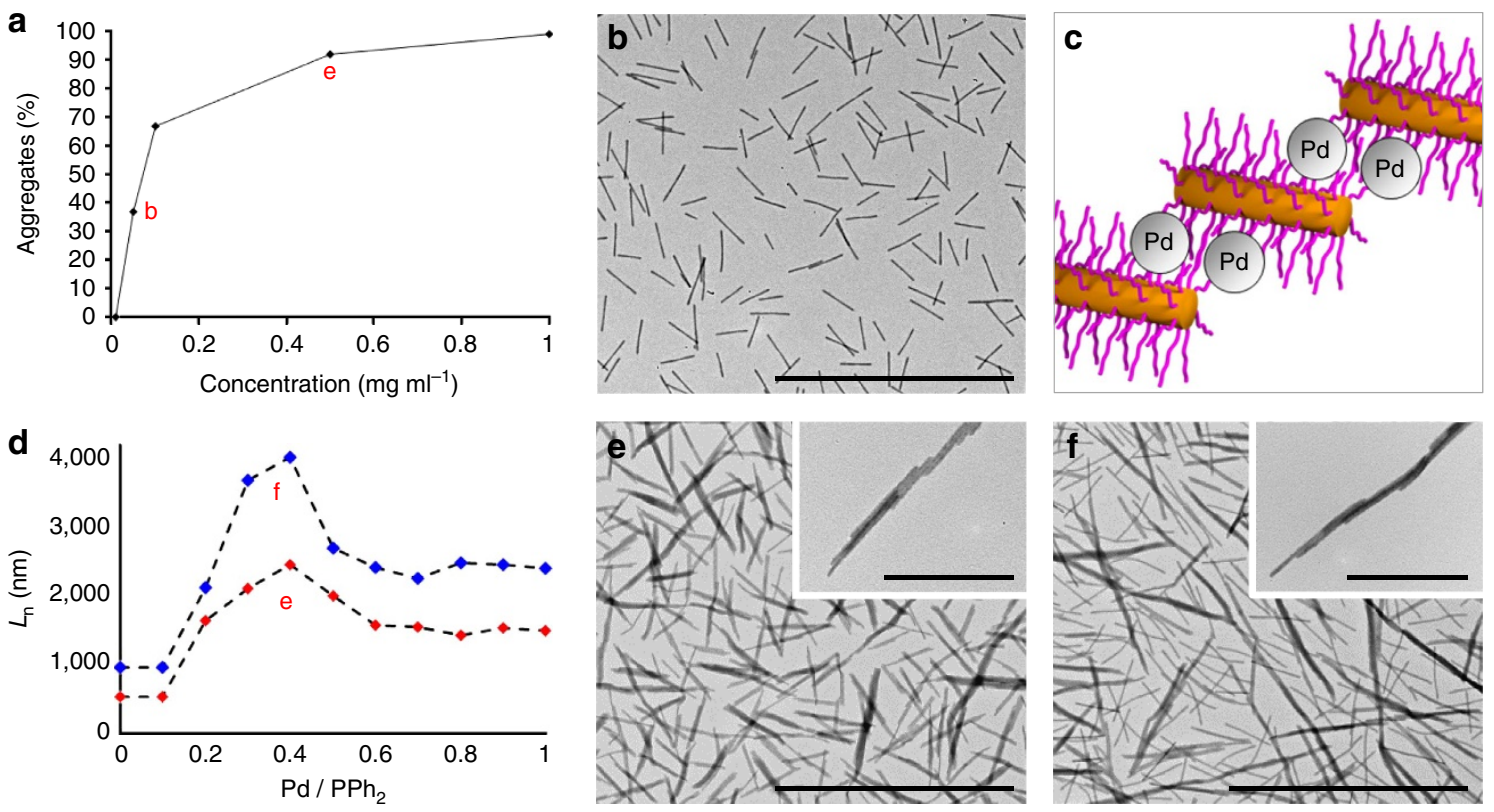

Figure 3 | Controlled coordination-driven hierarchical self-assembly. (a) Dependence of the percentage of micelles that aggregate into linear fibres on initial micelle concentration, $24 \mathrm{~h}$ after addition of $\mathrm{Pd}_{2}(\mathrm{dba})_{3}(0.4$ equiv. $\mathrm{Pd}(0)$ ). Labelled points $(\mathbf{b}, \mathbf{e})$ correspond to TEM images $(\mathbf{b}, \mathbf{e})$, respectively. (b) TEM image of $\mathbf{M}_{\mathbf{5 4 5}}\left(0.05 \mathrm{mg} \mathrm{ml}^{-1}\right) 24 \mathrm{~h}$ after addition of $\mathrm{Pd}_{2}(\mathrm{dba})_{3}$. (c) Schematic depiction of the intermicelle crosslinking between the coronas of two adjacent but offset micelles. (d) Mean fibre length $\left(L_{n}\right)$ as a function of normalized $\operatorname{Pd}(0)$ concentration for the coordination-driven hierarchical self-assembly of cylindrical $\mathbf{B C P} \mathbf{P}^{\mathbf{P}}$ micelle subunits $\mathbf{M}_{\mathbf{5 4 5}}\left(L_{n}=545 \mathrm{~nm}, L_{\mathrm{w}} / L_{\mathrm{n}}=1.05\right.$; red data points $)$ and $\mathbf{M}_{\mathbf{9 7 0}}\left(L_{\mathrm{n}}=970 \mathrm{~nm}, L_{\mathrm{w}} / L_{\mathrm{n}}=1.04\right.$; blue data points) at $0.5 \mathrm{mg} \mathrm{ml}^{-1}$ in EtOAc (see Supplementary Fig. 21 for an enlarged graph). Labelled points (e,f) correspond to TEM images (e,f), respectively. (e) TEM images of $\mathbf{M}_{\mathbf{5 4 5}}\left(0.5 \mathrm{mg} \mathrm{ml}^{-1}\right) 24 \mathrm{~h}$ after addition of $\mathrm{Pd}_{2}(\mathrm{dba})_{3}(0.4$ equiv. $\mathrm{Pd}(0))$. (f) TEM images of $\mathbf{M}_{\mathbf{9 7 0}}\left(0.5 \mathrm{mg} \mathrm{ml}^{-1}\right) 24 \mathrm{~h}$ after addition of $\mathrm{Pd}_{2}(\mathrm{dba})_{3}(0.4$ equiv. $\mathrm{Pd}(0))$. Scale bars correspond to $5,000 \mathrm{~nm}$ in main images and $1,000 \mathrm{~nm}$ in insets. 
intermicelle crosslinking by $\mathrm{Pd}(0)$ coordination. Once several intermicelle crosslinks are established between adjacent micelles during the initial coordination phase of $\operatorname{Pd}(0)$ to $\mathbf{B C} \mathbf{P}^{\mathbf{P}}$ micelles, the resulting aggregate is likely to be kinetically trapped. As a consequence of this trapping effect together with the high aspect ratio of the cylindrical micelle building blocks, the majority of micelles would be expected to aggregate offset from one another (Fig. 3c). This explains the observation of a predominantly linear extension of the resulting fibres rather than lateral growth to yield two-dimensional structures. Higher micelle concentrations would be expected to favour larger degrees of aggregation and therefore the formation of longer micelles, as was detected (Fig. 3a). The $\operatorname{Pd}(0)$ :phosphine ratio also has a substantial influence on the fibre length, but the relationship is more complex. On one hand, increased amounts of $\operatorname{Pd}(0)$ would be expected to favour intermicelle crosslinking and micelle aggregation, and should therefore increase fibre length. However, to form an intermicelle crosslink a $\operatorname{Pd}(0)$ centre must bind at least two phosphine groups from different micelles. At higher $\operatorname{Pd}(0)$ :phosphine ratios the probability of two phosphines being available to coordinate to $\operatorname{Pd}(0)$ would decrease, thereby favouring a lower degree of aggregation. As a result of these two competing effects, a maximum in a plot of fibre length versus $\operatorname{Pd}(0)$ :phosphine ratio is anticipated, and in fact, observed (Fig. 3d).

Complex superstructures by hierarchical self-assembly. Recent work has shown that amphiphilic block co-micelles can be used as building blocks for the assembly of a range of hierarchical superstructures ${ }^{36,37,42-44}$. The coordination-driven self-assembly strategy for cylindrical $\mathbf{B C P}^{\mathbf{P}}$ micelles described here can be extended to the assembly of block co-micelles of low amphiphilicity containing spatially segregated regions of coronal chemistry. For example, A-B-A triblock co-micelles $\left(L_{\mathrm{n}}=215 \mathrm{~nm}, L_{\mathrm{w}} / L_{\mathrm{n}}=1.03\right)$ with terminal A blocks of $\mathbf{B C P}^{\mathbf{P}}$ and a central B block of PFS- $b$-PDMS (PDMS, polydimethylsiloxane), prepared by living CDSA via the addition of $\mathbf{B C P}^{\mathbf{P}}$ to PFS- $b$ PDMS seeds $\left(L_{\mathrm{n}} \sim 150 \mathrm{~nm}\right)$, also afford long linear fibres as observed by TEM after the addition of $\operatorname{Pd}_{2}(\mathrm{dba})_{3}$. However, in these cases the degree of side-by-side aggregation appears markedly reduced so that essentially linear chains of micelles develop (Fig. 4a-c and Supplementary Fig. 22). When A-B-A triblock co-micelles $\left(L_{\mathrm{n}}=465 \mathrm{~nm}, L_{\mathrm{w}} / L_{\mathrm{n}}=1.04\right)$ were prepared with a longer central PFS- $b$-PDMS segment $\left(L_{\mathrm{n}} \sim 400 \mathrm{~nm}\right)$ and shorter $\mathbf{B C P} \mathbf{P}^{\mathbf{P}}$ end blocks $\left(L_{\mathrm{n}} \sim 30 \mathrm{~nm}\right)$, short linear and branched single chains of micelles, as well as cyclic aggregates, were observed (Supplementary Fig. 23). These results indicate that replacement of the phosphine-containing corona with regions of non-coordinating PDMS reduces the likelihood of side-by-side aggregation of the micelle-building blocks. Finally, B-A-B micelles were prepared $\left(L_{\mathrm{n}}=360 \mathrm{~nm}, L_{\mathrm{w}} / L_{\mathrm{n}}=1.05\right)$, wherein the phosphine functionality was spatially isolated within the corona of the central A blocks $\left(L_{\mathrm{n}} \sim 300 \mathrm{~nm}\right)$. In this case, as a result of the terminal PFS- $b$-PDMS B blocks lacking phosphine functionality, the formation of linear fibres became unfavourable and, on addition of $\mathrm{Pd}_{2}(\mathrm{dba})_{3}$, coordination-driven assembly yielded stacked structures in which aggregation proceeded perpendicular to the central A block (Supplementary Fig. 24). Both the concentration of micelles and stoichiometry were observed to have an influence on the final dimensions of the resulting structures, albeit to a lesser extent than in the experiments using pure $\mathbf{B C P} \mathbf{P}^{\mathbf{P}}$ micelles.

One of the principal advantages of this type of coordinationdriven self-assembly is that hierarchical superstructures can be prepared by the use of orthogonal self-assembly techniques. For example, when further PFS-based BCP was added to a solution of linear fibres of $\mathbf{B C P} \mathbf{P}^{\mathbf{P}}$ micelles crosslinked with $\mathrm{Pd}(0)$, additional
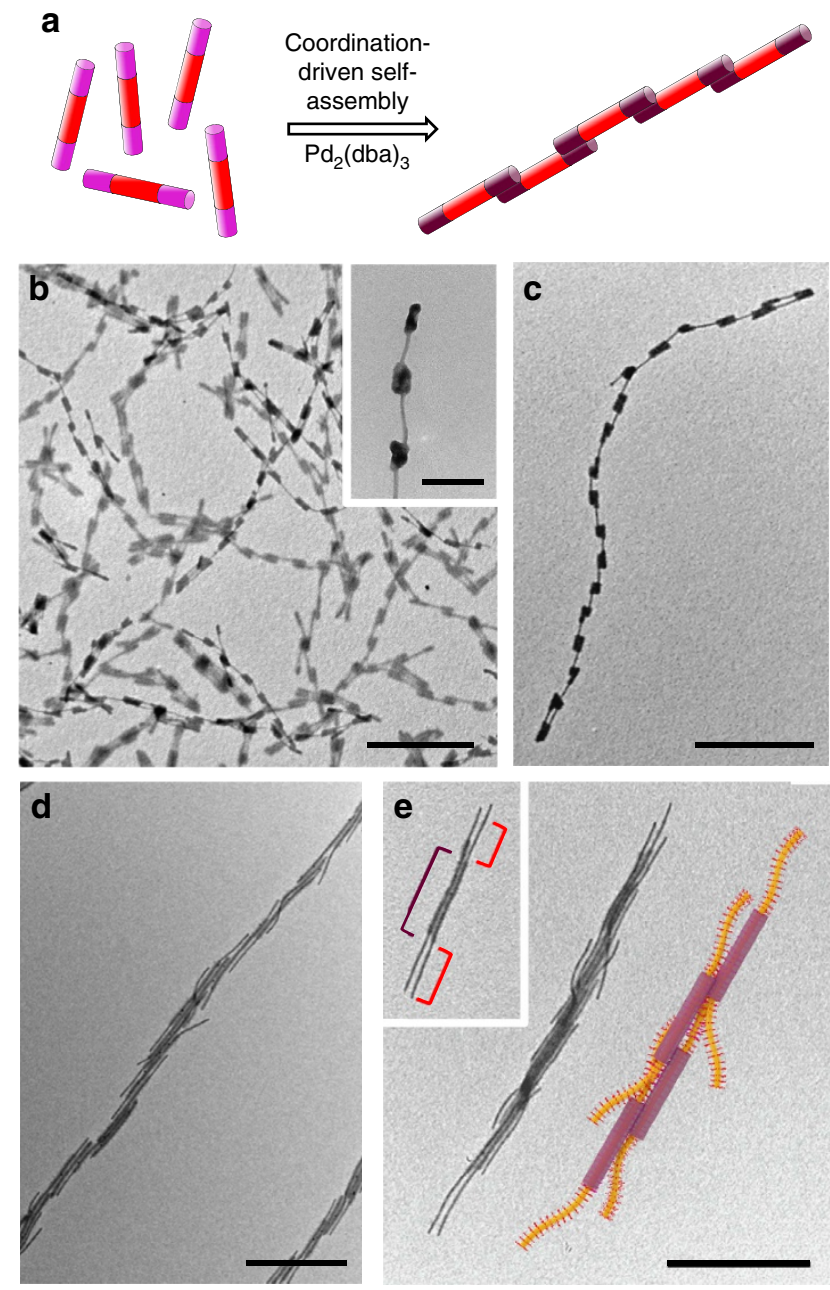

Figure 4 | Complex superstructures by hierarchical self-assembly.

(a) Schematic depiction of the coordination-driven self-assembly process. Red, pink and purple blocks in schematics correspond to PFS-b-PDMS, $\mathbf{B C P} \mathbf{P}$ and $\mathrm{Pd}$-coordinated $\mathbf{B C P} \mathbf{P}$, respectively. TEM images of A-B-A triblock co-micelles $\left(L_{n}=215 \mathrm{~nm}, L_{\mathrm{w}}=220 \mathrm{~nm}, L_{\mathrm{w}} / L_{\mathrm{n}}=1.03\right)$ after coordination of $\mathrm{Pd}_{2}(\mathrm{dba})_{3}\left(0.4\right.$ equiv. $\mathrm{Pd}(0)$ ) at a micelle concentration of $1 \mathrm{mg} \mathrm{ml}^{-1}$ to favour longer multicompartment chains (b) and after dilution to $0.1 \mathrm{mg} \mathrm{ml}^{-1}$ (c). (d,e) TEM images of branched nanostructures $24 \mathrm{~h}$ after the addition of $\mathrm{PFS}_{63}-b-\mathrm{PDMS}_{513}$ (denoted by red bracket in inset) to a solution of linear coordinated fibres (denoted by purple bracket in inset). A schematic representation of the hairy rod-like superstructures is shown in e. Scale bars correspond to $1,000 \mathrm{~nm}$ in main images and $200 \mathrm{~nm}$ in inset.

growth occurred from the exposed micelle termini by living CDSA to generate hairy rod-like superstructures observable by TEM (Fig. 4d,e and Supplementary Fig. 25). Owing to the living nature of CDSA, the lengths of the supermicelle arms are dependent on the ratio of pre-existing Pd-coordinated micelles to added unimer. As a relatively low level of metal loading is required for coordination-driven hierarchical self-assembly, the degree of crosslinking and the length of the coronal segments appear to be insufficient to block the termini of the cylindrical micelles and prevent further growth, as has been previously observed ${ }^{42}$.

Micelle-based thin films. The preparation of porous hybrid materials and nematic hydrogels ${ }^{22}$ using micelles has been reported $^{51,52}$, although, to the best of our knowledge, no macroscopic materials have been prepared entirely from BCP micelles via hierarchical assembly. When coordination-driven self- 
assembly was attempted with a solution of $\mathbf{B C P}^{\mathbf{P}}$ micelles in EtOAc with a concentration $>1 \mathrm{mg} \mathrm{ml}^{-1}$, significant aggregation and precipitation of the micelles occurred (Supplementary Fig. 26). The suspensions were shaken to disperse the precipitated material, and drop-cast samples were observed by optical microscopy and TEM (Supplementary Fig. 27). Both techniques revealed that the aggregated material contained regions of interwoven fibres comprised of coordinated micelles.

As the fibres described here are strengthened by intramicelle metal crosslinking, they represent promising stable building blocks for the bottom-up preparation of micelle-based materials. To prepare uniform bulk micelle films, an EtOAc solution of linear fibres of coordinated $\mathbf{B C P}^{\mathbf{P}}$ micelles was layered on top of deionized water in a circular glass beaker. The organic solvent was allowed to evaporate, which led to the formation of a thin, selfsupporting film at the water-air interface (Fig. 5a). The micelle film was subsequently removed and manipulated in air (Fig. 5b,c). The thickness of the film could be varied by changing the ratio of the amount of micelle material to the diameter of the container used, affording materials that varied from pale yellow for thin samples to orange for thicker examples (Supplementary Fig. 28). According to nanoindentation measurements (Supplementary Fig. 29), the hardness and Young's modulus of drop-cast films were determined to be $192.5 \pm 3.9 \mathrm{MPa}$ and $1.2 \pm 0.4 \mathrm{GPa}$, respectively. For calibration, these values are in the approximate range expected for polymeric thermoplastic materials.

To prepare micelle-based films suitable for morphological and topological analyses, solutions of Pd-coordinated fibres of $\mathbf{M}_{\mathbf{9 7 0}}$ were drop-cast and the resulting samples were subsequently investigated by atomic force microscopy (AFM), scanning electron microscopy (SEM), optical microscopy and transmission electron microtomography (TEMT) ${ }^{53,54}$ after solvent evaporation. Regions of interwoven coordinated fibres could be clearly observed by all four techniques (Fig. $5 \mathrm{~d}-\mathrm{f}$ and Supplementary Fig. 30). Significantly, three levels of hierarchy are evident by AFM (Fig. 5d and Supplementary Fig. 31); the bulk network material, the interwoven coordinated fibres and the individual BCP $^{\mathbf{P}}$ micelles. Moreover, TEMT analysis allowed for the rendering of a $3 \mathrm{D}$ image of the hierarchical material, wherein the aligned iron-rich micelle cores were clearly observed (Fig. $5 f$ and Supplementary Fig. 32).

\section{Discussion}

In summary, we describe a reversible, coordination-driven hierarchical self-assembly strategy for cylindrical micelles that allows access to micelle-based microfibres and thin films. Monodisperse cylindrical BCP micelle subunits, with phosphine ligands selectively located within their coronas, form micrometrelength fibres of staggered cylindrical BCP micelle-building blocks on treatment with a source of $\operatorname{Pd}(0)$. The final fibre lengths can be systematically varied by changing the reaction stoichiometry, overall micelle concentration or aspect ratio of micelle subunits. Moreover, as a significant step towards the preparation of functional macroscopic micelle-based materials, samples of the coordinated linear fibres can be dried to yield robust, self-
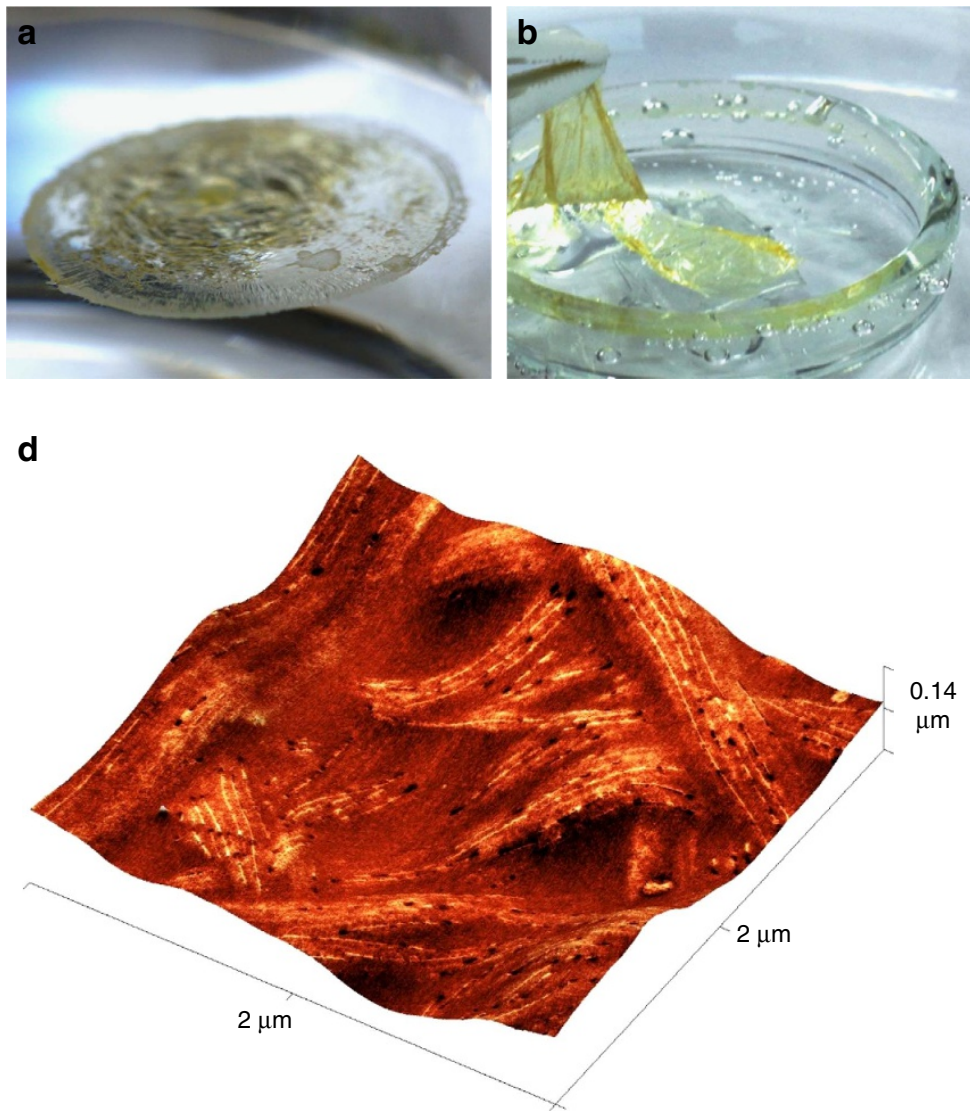
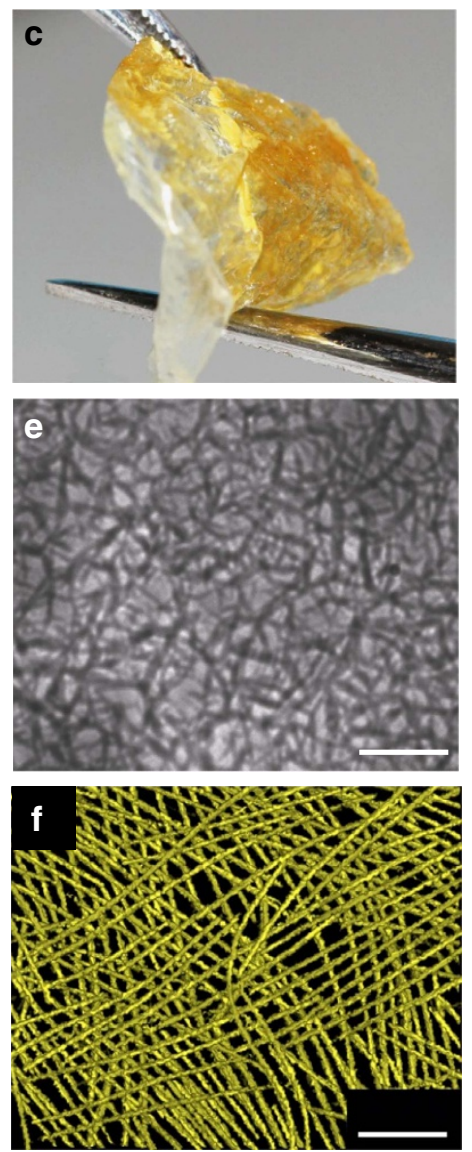

Figure $\mathbf{5}$ | Micelle-based thin films. Photographic images of a micelle film prepared by drying a sample of linear fibres of coordinated $\mathbf{M}_{\mathbf{9 7 0}}$; floating on water (a), in the process of being removed from the water surface (b) and being manipulated in air (c). AFM image displaying phase information superimposed on topographical height data (d), bright-field optical microscopy image (e) and rendered 3D image from TEMT (f) of a drop-cast sample of the solution of linear fibres of coordinated $\mathbf{M}_{\mathbf{9 7 0}}$. Scale bars correspond to 10 and $0.2 \mu \mathrm{m}$ in $\mathbf{e}$ and $\mathbf{f}$, respectively. 
supporting thin films. As control exists over the dimensions of the starting $\mathrm{BCPs}$, the micelles and their segments, and the linear fibres, modifications at each of these levels of structural hierarchy would be expected to significantly influence the morphology and properties of the resulting macroscopic materials. This presents an opportunity to fabricate robust soft-matter-based constructs for applications as electroactive fibres and films, membranes for separation, nanocomposite materials and as catalyst supports.

\section{Methods}

Equipment and materials. The BCPs poly(ferrocenyldimethylsilane $)_{63}-b$-polydimethylsiloxane ${ }_{513}\left(\mathrm{PFS}_{63}-b-\mathrm{PDMS}_{513}\right), \mathrm{PFS}_{68}-b-\mathrm{PMVS}_{670}$ (PMVS, poly (methylvinylsiloxane)) and $\mathrm{PFS}_{60}-b$ - PMVS $_{574}$ were prepared by literature procedures (Supplementary Table 1$)^{55}$. All air- or moisture-sensitive reactions were carried out in oven $\left(200^{\circ} \mathrm{C}\right)$-dried glassware under a positive nitrogen pressure using standard Schlenk techniques or in an MBraun MB150B-G glove box under argon. THF for living anionic polymerizations and photochemical reactions was pre-dried with sodium and distilled off sodium/benzophenone before use. Anhydrous solvents were obtained using a modified Grubbs system of alumina columns manufactured by Anhydrous Engineering, and degassed by bubbling nitrogen before use. Tetramethylethylenediamine and 1,3,5-trimethyl-1,3,5 trivinylcyclotrisiloxane $\left(\mathrm{V}_{3}\right)$ were pre-dried with calcium hydride and distilled before use. Chlorodimethylvinylsilane and chlorotrimethylsilane were distilled before use. Hexamethylcyclotrisiloxane $\left(D_{3}\right)$ was dissolved in pentane and pre-dried with calcium hydride before being dried in vacuo and sublimed onto a $-5^{\circ} \mathrm{C}$ cold finger. Diaceto palladium(II) and bis(dibenzylideneacetone) palladium $(0)$ were purchased from Sigma-Aldrich and used without further purification. Tris(dibenzylideneacteone) dipalladium $(0)$ was purchased from Sigma-Aldrich, and purified by a literature procedure ${ }^{56}$. All other commercially available compounds were used without further purification. Standard laboratory solvents were purchased from VWR or Fisher Scientific. Solvents for self-assembly were filtered (polytetrafluoroethylene membrane with $0.45 \mu \mathrm{m}$ pore size) before use. Ethyl acetate for the self-assembly of phosphine-containing polymers was pre-dried with $\mathrm{CaH}_{2}$, distilled, filtered and stored under argon. Deionized water was used for the preparation of micelle-based films.

Polymer characterization. The molecular weights of the $\mathrm{BCPs}$ were determined by combining the $M_{\mathrm{n}}$ of PFS homopolymers from matrix-assisted laser desorption/ ionization time of flight (MALDI-TOF) mass spectrometry measurements, with the block ratio obtained by ${ }^{1} \mathrm{H}$ NMR spectroscopy. MALDI-TOF mass spectrometry measurements of PFS homopolymers were performed using a Bruker Ultraflextreme running in linear mode. Samples were prepared using a trans-2-[3-(4-tert-butylphenyl)-2-methyl-2-propenylidene]malononitrile matrix $\left(20 \mathrm{mg} \mathrm{ml}^{-1}\right.$ in THF) and the polymer sample $\left(2 \mathrm{mg} \mathrm{ml}^{-1}\right.$ in THF), mixed in a 10:1 (v/v) ratio. Approximately $1 \mu \mathrm{l}$ of the mixed solution was deposited onto a stainless-steel sample plate and allowed to dry in air. The $M_{\mathrm{n}}$ of the PFS homopolymers obtained by gel permeation chromatography (GPC) using laser light scattering to determine the absolute molecular weights corresponded well with those obtained by MALDI-TOF mass spectrometry. Theoretical molecular weights for the functionalized BCPs were used for yield calculations. Polydispersity indices $\left(\mathrm{PDI}=M_{\mathrm{w}} / M_{\mathrm{n}}\right)$ of all the polymers were obtained by GPC using a Viscotek VE 2001 Triple-detector gel permeation chromatograph equipped with automatic sampler, pump, injector, inline degasser, column oven $\left(30^{\circ} \mathrm{C}\right.$ ), styrene/divinylbenzene columns (pore sizes of between 500 and 100,000 $)$ ), VE 3580 refractometer, four-capillary differential viscometer, VE $3210 \mathrm{UV} / \mathrm{Vis}$ detector $(\lambda=450 \mathrm{~nm})$ and VE 270 dual-angle laser light-scattering detector $\left(7^{\circ}\right.$ and $\left.90^{\circ}\right)$. THF stabilized with $0.025 \%$ butylated hydroxytoluene (Fisher) was used as the chromatography eluent, at a flow rate of $1.0 \mathrm{ml} \mathrm{min}^{-1}$. Samples were dissolved in the eluent $\left(2 \mathrm{mg} \mathrm{ml}^{-1}\right)$ and filtered (polytetrafluoroethylene (PTFE) membrane with $0.45 \mu \mathrm{m}$ pore size) before analysis. Calibration of the detectors was performed using polystyrene standards (Viscotek). The percentage hydrophosphination of $\mathbf{B C P}^{\mathbf{P}}$ was calculated by both ${ }^{31} \mathrm{P}$ NMR and ${ }^{1} \mathrm{H}$ NMR spectroscopy, either by comparison to an internal standard, or by measuring the reduction of signals corresponding to vinyl group protons and the emergence of peaks corresponding to the hydrophosphinated product, respectively.

NMR spectroscopy. ${ }^{1} \mathrm{H},{ }^{13} \mathrm{C},{ }^{29} \mathrm{Si}$ and ${ }^{31} \mathrm{P}$ NMR spectra were recorded using either a JEOL Eclipse $300 \mathrm{MHz}$, JEOL Eclipse $400 \mathrm{MHz}$, Varian VNMR $400 \mathrm{MHz}$ or Varian VNMR $500 \mathrm{MHz}$ spectrometer. The chemical shifts $(\delta)$ are reported in parts per million (p.p.m.) and the coupling constants $(J)$ in Hertz (Hz). Chemical shifts were referenced to residual dichloromethane at $\delta 5.32$ p.p.m. $\left({ }^{1} \mathrm{H}\right)$, and benzene at $\delta 7.14$ p.p.m. $\left({ }^{1} \mathrm{H}\right)$ and $\delta 128.06$ p.p.m. $\left({ }^{13} \mathrm{C}\right) .{ }^{1} \mathrm{H}$ NMR integrations for the polymers were calculated after setting the methyl protons $(6 \mathrm{H})$ of PFS to $378 \mathrm{H}$ for $\mathrm{PFS}_{63}-b-\mathrm{PDMS}_{513}, 408 \mathrm{H}$ for $\mathrm{PFS}_{68}-b-\mathrm{PMVS}_{670}$ and $360 \mathrm{H}$ for $\mathrm{PFS}_{60}-b-\mathrm{PMVS}_{574}$.

Photoirradiation. Photoirradiation experiments were carried out with Pyrex glass-filtered emission from a water-cooled $125 \mathrm{~W}$ medium-pressure mercury lamp (Photochemical Reactors Ltd.). Pyrex glass filters out emission at wavelengths below $300 \mathrm{~nm}$. The emission lines of the mercury lamp were 577-579, 546, 436, 408-405, 366-365, 334, 313, 302, 297, 289, 280, 270, 265 and $254 \mathrm{~nm}$. An ethylene glycol/deionized water bath in conjunction with a thermostat was used to maintain constant temperatures during photoirradiation.

Ultrasonication. A Hielsher UP100H $100 \mathrm{~W}$ ultrasonic processor equipped with a titanium sonotrode was used to prepare seed micelles. For oxygen-sensitive samples, sonication was conducted under a positive nitrogen atmosphere.

Transmission electron microscopy. Samples for TEM were prepared by drop-casting $5 \mu \mathrm{l}$ of the micelle solution onto a carbon-coated copper grid on a piece of filter paper, to remove excess solvent. Bright-field TEM micrographs were obtained on a JEOL1200EX II microscope operating at $120 \mathrm{kV}$ and equipped with an SIS MegaViewIII digital camera. Stained samples were prepared as described above, aged for $24 \mathrm{~h}$ and then exposed to $\mathrm{OsO}_{4}$ vapour for $16 \mathrm{~h}$ in a sealed Petri dish. For the statistical length analysis, images were analysed using the ImageJ software package developed at the US National Institute of Health. A minimum of 200 individual cylinders were carefully traced by hand to determine the contour length. From these data $L_{\mathrm{n}}$ and $L_{\mathrm{w}}$ of each sample of cylindrical micelles were calculated using equations (1) and (2), respectively (where $L$ is the length of an object and $N$ is the number of objects).

$$
\begin{gathered}
L_{\mathrm{n}}=\frac{\sum_{i=1}^{n} N_{i} L_{i}}{\sum_{i=1}^{n} N_{i}} \\
L_{\mathrm{w}}=\frac{\sum_{i=1}^{n} N_{i} L_{i}^{2}}{\sum_{i=1}^{n} N_{i} L_{i}}
\end{gathered}
$$

For the statistical length analysis of linear aggregates prepared by coordinationdriven self-assembly, a minimum of 50 individual fibres were carefully traced by hand to determine the contour length. From these results $L_{\mathrm{n}}$ and $L_{\mathrm{w}}$ of each sample of linear aggregates were calculated using equations (1) and (2).

EDX spectroscopic analysis. Complementary EDX measurements were conducted on a JEOL JEM 2010 microscope operated at $200 \mathrm{kV}$ and equipped with a Kodak Electron Image Film SO-163 digital camera and an Oxford Instruments ISIS 310 system with silicon detector and ATW using a $35 \mathrm{~nm}$ spot size. All EDX experiments were conducted on the carbon-coated copper grids used for TEM.

Bright-field optical microscopy. For the optical microscopy, sample solutions were drop-cast onto a glass slide. Imaging was carried out using a custom-built microscope with a 1.3 numerical aperture $\times 100$ Plan-Neufluar, Zeiss objective lens. Movement of the field of view around the sample is achieved with a motorized $\mathrm{x}-\mathrm{y}$ stage (MS2000, ASI) and a piezo-electric objective focussing system (Mipos 140 PL, Piezosystem Jena).

Atomic force microscopy. Samples for AFM were prepared by spin-coating $10 \mu \mathrm{l}$ of the micelle solution onto a freshly cleaved mica substrate or gold-coated mica. Tapping-mode images were obtained using a Multimode $\mathrm{V}$ atomic force microscope with a Nanoscope V controller. Nanosensors PPP NCHR10 cantilevers with a $10 \mathrm{~nm}$ rotated monolithic silicon tip were used. Imaging was conducted under ambient conditions. Images were analysed using Gwyddion, an open-source software programme.

Scanning electron microscopy. Samples for SEM were prepared by drop-casting the sample solutions onto gold-coated mica substrates. Imaging was performed using a JEOL 5600LV SEM microscope.

Dynamic light scattering. DLS measurements $\left(173^{\circ}\right)$ were performed using Malvern Zetasizer Nano Series spectrometer equipped with a $633 \mathrm{~nm}$ red laser. Solutions of between 0.5 and $1 \mathrm{mg} \mathrm{ml}^{-1}$ were analysed in glass cuvettes at $20^{\circ} \mathrm{C}$. Dry and degassed ethyl acetate was used as the continuous phase for all experiments. In the case of the reversibility experiments, reproducible DLS data could not be obtained due to the strong colour of the molecular $\mathrm{Pd}(0)$ species formed during process.

Nanoindentation. Hardness and modulus tests of thick cylindrical micelle films drop-cast onto silicon wafer were performed at ambient temperature on a Hysitron UBI-Nanoindenter equipped with a $90^{\circ}$ conical diamond tip possessing a nominal $1 \mu \mathrm{m}$ curvature radius (specifically designed for use with polymers). AFM was conducted in tapping mode to (i) map the surface features over a $10 \times 10 \mu \mathrm{m}^{2}$ specimen region and (ii) select areas with minimal surface roughness for indentation tests within the region of interest. Indentations were load-controlled at forces of $35,50,75,100$ and $150 \mu \mathrm{N}$, leading to penetration depths ranging from ca. 80 to $300 \mathrm{~nm}$. Corresponding loading rates were applied at 16, 23, 35, 47 and $70 \mu \mathrm{N} \mathrm{s}^{-1}$, respectively, whereas unloading rates were maintained at the maximum load per second. Measurements from loading-unloading cycles such as the one provided in Supplementary Fig. 29 were replicated 11 times from different 
specimen areas. The hardness $(H)$ of the drop-cast cylindrical micelle film from nanoindentation measurements is calculated from equation (3).

$$
H=\frac{P_{\max }}{A\left(h_{\mathrm{c}}\right)}
$$

$P_{\max }$ denotes the pressure measured at the maximum penetration depth, $A$ is the area of contact between the tip and the sample (calculated using an empirical tip area function based on the specific tip geometry), and $h_{\mathrm{c}}$ represents the contact depth. According to equation (3), $H$ of the cylindrical micelle film is determined to be $192.5 \pm 3.9 \mathrm{MPa}$. Similarly, a reduced Young's modulus $\left(E_{\mathrm{r}}\right)$ can likewise be determined from equation (4).

$$
E_{\mathrm{r}}=\frac{S \sqrt{\pi}}{2 \sqrt{A\left(h_{\mathrm{c}}\right)}}
$$

$S$ is the stiffness discerned from the instantaneous change in load pressure at the point of unloading (that is, $\mathrm{d} P / \mathrm{d} h$ evaluated at $h_{\max }$ identified in Supplementary Fig. 29). The Young's modulus of the micelle film $(E)$ can then be computed from the reduced Young's modulus by knowing the modulus of the indentation tip $\left(E_{\mathrm{i}}\right)$ and the corresponding Poisson's ratios ( $v$ and $v_{\mathrm{i}}$, respectively; equation (5)).

$$
\frac{1}{E_{\mathrm{r}}}=\frac{(1-v)^{2}}{E}+\frac{\left(1-v_{\mathrm{i}}\right)^{2}}{E_{\mathrm{i}}}
$$

The values of $E_{\mathrm{i}}$ and $v_{\mathrm{i}}$ used here for the diamond tip are 1,141 GPa and 0.07, respectively. Since Mott and Roland ${ }^{57}$ point out that many thermoplastics possess a Poisson's ratio between 0.3 and 0.5 , we presume here that $v \approx 0.4$, in which case the Young's modulus of the micelle film is $1.2 \mathrm{GPa}$ (with a variation of $\pm 0.4 \mathrm{GPa}$ as $v$ changes by \pm 0.1 ). Because each copolymer molecule contains a substantial polysiloxane block, a Poisson's ratio approaching 0.5 is reasonable. The crystallizable block that regulates copolymer self-assembly and contributes to micelle stiffness is, however, likely to reduce the overall Poisson's ratio of the micelle film, as well as cause the plastic deformation evident in Supplementary Fig. 29.

Low-voltage SEM. Backscattered-electron images of uncoated cylindrical micelle films drop-cast onto carbon-coated hexagonal grids were acquired by field-emission SEM performed on an ultrahigh-resolution FEI Verios 460l Schottkey emitter microscope operated at $1 \mathrm{kV}$.

Transmission electron microtomography. 3D TEMT images of cylindrical micelle films drop-cast onto carbon-coated hexagonal grids were generated from a series of TEM tilt images collected from $-65^{\circ}$ to $+65^{\circ}$ at an angular increment of $1.5^{\circ}$ on a Gatan K2 Summit direct detection camera mounted on an automated FEI Tecnai F20 field-emission microscope operated at $200 \mathrm{kV}$. Image alignment was performed without the use of fiducial markers by modelling the high-precision goniometer ${ }^{58}$. The resulting aligned and mass-normalized image sets were subjected to reconstruction using the filtered ( $r$-weighted) back-projection algorithm ${ }^{59}$, and 3D volume elements were produced by qualitative pixel thresholding.

Preparation of BCPP. Diphenylphosphine $(2.00 \mathrm{ml}, 2.14 \mathrm{~g}, 11.5 \mathrm{mmol})$ was added to a solution of PFDMS $_{61}-b$-PMVS - $_{574}(0.46 \mathrm{~g}, 4.1 \mathrm{mmol}$ vinyl groups $)$ in dry THF $(10 \mathrm{ml})$ under a nitrogen atmosphere. The reaction mixture was irradiated $3 \mathrm{~cm}$ from a mercury lamp at room temperature for $24 \mathrm{~h}$. The solution was concentrated in vacuo, twice precipitated into degassed $\mathrm{MeOH}$ and dried in vacuo to afford the pure $\mathrm{BCP}, \mathbf{B C P}^{\mathrm{P}}\left(0.54 \mathrm{~g}, 74 \%, 35 \%\right.$ hydrophosphination by $\left.{ }^{1} \mathrm{H} \mathrm{NMR}\right)$ as an orange solid (Supplementary Fig. 1 and Supplementary Table 1). ${ }^{31} \mathrm{P}$ NMR $(202 \mathrm{MHz}$ $\left.\mathrm{C}_{6} \mathrm{D}_{6}\right): \delta-9.4\left(\right.$ br s, $\left.-\mathrm{PPh}_{2}\right) ;{ }^{31} \mathrm{P}$ NMR $\left(202 \mathrm{MHz} ; \mathrm{CDCl}_{3}\right): \delta-9.1$ (br s, $-\mathrm{PPh}_{2}$ ); ${ }^{31} \mathrm{P}$ NMR (202 MHz; EtOAc): $\delta-8.7\left(\right.$ br s, $\left.-\mathrm{PPh}_{2}\right) ;{ }^{1} \mathrm{H}$ NMR $\left(500 \mathrm{MHz} ; \mathrm{C}_{6} \mathrm{D}_{6}\right): \delta$ 0.21-0.38 (1728H, br m, siloxane $\left.\mathrm{SiCH}_{3}\right), 0.56\left(360 \mathrm{H}, \mathrm{s}, \mathrm{Si}\left(\mathrm{CH}_{3}\right)_{2}\right), 0.89(400 \mathrm{H}$, br $\left.\mathrm{m}, \mathrm{SiCH}_{2}\right), 2.29\left(400 \mathrm{H}\right.$, br m, $\left.\mathrm{CH}_{2} \mathrm{P}\right), 4.12(240 \mathrm{H}, \mathrm{s}, \mathrm{CpH}), 4.29(240 \mathrm{H}, \mathrm{s}, \mathrm{CpH})$, 5.90-6.00 $\left(750 \mathrm{H}\right.$, br m, $\left.\mathrm{CHCH}_{2}\right), 6.09-6.26\left(375 \mathrm{H}\right.$, br m, $\left.\mathrm{CHCH}_{2}\right), 7.07-7.17$ $(1200 \mathrm{H}$, br m, $\mathrm{ArH})$ and $7.54-7.57(800 \mathrm{H}$, br m, $\mathrm{ArH}) ;{ }^{13} \mathrm{C} \mathrm{NMR}(100 \mathrm{MHz}$, $\left.\mathrm{C}_{6} \mathrm{D}_{6}\right): \delta-0.5\left(\mathrm{Si}\left(\mathrm{CH}_{3}\right)_{2}\right),-0.1\left(\mathrm{SiCH}_{3}\right), 13.6\left(\mathrm{~d}, J=8.2 \mathrm{~Hz}, \mathrm{SiCH}_{2}\right), 21.4$ $\left(\mathrm{d}, J=15.2 \mathrm{~Hz}, \mathrm{CH}_{2} \mathrm{P}\right), 71.8(2 \mathrm{CpC}), 71.9(\mathrm{CpCSi}), 73.7(2 \mathrm{CpC}), 128.7$ (br s, ArC), $133.3(\mathrm{~d}, J=18.2 \mathrm{~Hz}, \mathrm{ArC}), 133.7\left(\right.$ br s, $\left.\mathrm{CHCH}_{2}\right), 137.1$ (br s, $\mathrm{CHCH}_{2}$ ) and 139.8 $\left(\mathrm{d}, J=14.3 \mathrm{~Hz}, \mathrm{PC}_{\text {ipso }}\right.$ ). The polymer $\mathbf{B C P}^{\mathbf{P}}$ was treated with sulphur (1 equiv.) in dry and degassed THF to oxidize the phosphine moieties before GPC analysis. ${ }^{31} \mathrm{P}$ NMR (202 MHz; THF): $\delta 38.4$ (br s, $-\mathrm{P}(\mathrm{S}) \mathrm{Ph}_{2}$ ).

Preparation of cylindrical micelles. General procedure. In a sealed vial under an argon atmosphere, a solution of BCP in dry and degassed EtOAc $\left(1 \mathrm{mg} \mathrm{ml}^{-1}\right)$ was heated to $75^{\circ} \mathrm{C}$ with stirring for $1 \mathrm{~h}$. The pale yellow solution was allowed to cool and aged for 1 week. Polydisperse cylindrical micelles were observed by TEM analysis of the drop-cast solution (Supplementary Fig. 2).

Preparation of $\mathbf{B C P} \mathbf{P}^{\mathbf{P}}$ seed micelles. A solution of polydisperse cylindrical micelles of BCP $\mathbf{B C P}^{\mathbf{P}}$ in dry and degassed EtOAc $\left(1 \mathrm{mg} \mathrm{ml}{ }^{-1}\right)$ under a nitrogen atmosphere was cooled to $0{ }^{\circ} \mathrm{C}$ and sonicated with a sonotrode at $50 \%$ power for $1 \mathrm{~h}$ to afford monodisperse seed micelles $\left(L_{\mathrm{n}}=37 \mathrm{~nm}, L_{\mathrm{w}}=43 \mathrm{~nm}, L_{\mathrm{w}} / L_{\mathrm{n}}=1.16\right.$; Supplementary Fig. 3) as observed by TEM analysis. The same procedure was used for the preparation of monodisperse $\mathrm{PFS}_{63}-b$-PDMS ${ }_{513}$ seed micelles $\left(L_{\mathrm{n}}=41 \mathrm{~nm}\right.$, $\left.L_{\mathrm{w}}=49 \mathrm{~nm}, L_{\mathrm{w}} / L_{\mathrm{n}}=1.19\right)$

Preparation of monodisperse $\mathbf{B C P}^{\mathbf{P}}$ micelles. General procedure. In a glove box under an argon atmosphere, 5, 10, 20 and 40 equiv. of $\mathbf{B C} \mathbf{P}^{\mathbf{P}}$ unimer $\left(10 \mathrm{mg} \mathrm{ml}^{-1}\right.$ in THF) were added to stirred stock solutions of monodisperse seed micelles diluted in dry and degassed EtOAc (to achieve a final $\mathbf{B C P}^{\mathbf{P}}$ concentration of $1 \mathrm{mg} \mathrm{ml}^{-1}$ ). After addition the stirring was stopped and the mixtures aged for 1 week. Statistical length analysis of TEM images of the resulting nanostructures showed a linear growth dependence on the unimer-to-seed ratio (Supplementary Fig. 4 and Supplementary Table 2). In this study, negligible differences were observed between the CDSA behaviour of the non-phosphine-containing and phosphine-containing BCPs.

Preparation of monodisperse A-B-A micelles. A is $\mathbf{B C} \mathbf{P P}^{\mathbf{P}}$ and B is PFS- $b$-PDMS. In a glove box under an argon atmosphere, $200 \mu \mathrm{PFS}_{63}-b$ - $\mathrm{PDMS}_{513}$ seeds $\left(1 \mathrm{mg} \mathrm{ml}^{-1}\right.$ in EtOAc) were diluted in $900 \mu \mathrm{l}$ dry and degassed EtOAc. The seed solution was stirred and $20 \mu \mathrm{l}$ of a $\mathrm{PFS}_{63}-b$ - $\mathrm{PDMS}_{513}$ unimer solution $\left(10 \mathrm{mg} \mathrm{ml}^{-}\right.$ in THF) was added dropwise. After addition the stirring was stopped and the mixture aged overnight. The micelle solution was stirred and $80 \mu \mathrm{l}$ of a $\mathbf{B C P}^{\mathbf{P}}$ unimer solution $\left(10 \mathrm{mg} \mathrm{ml}^{-1}\right.$ in THF) was added dropwise. After addition the stirring was stopped and the mixture aged for 1 week. Monodisperse cylindrical micelles were observed by TEM analysis of a drop-cast of the solution

$\left(L_{\mathrm{n}}=215 \mathrm{~nm}, L_{\mathrm{w}}=222 \mathrm{~nm}, L_{\mathrm{w}} / L_{\mathrm{n}}=1.03\right)$.

In a glove box under an argon atmosphere, $200 \mu \mathrm{PFS}_{63}-b$-PDMS $\mathrm{PD}_{513}$ seeds $\left(1 \mathrm{mg} \mathrm{ml}^{-1}\right.$ in EtOAc) were diluted in $900 \mu \mathrm{l}$ dry and degassed EtOAc. The seed solution was stirred and $60 \mu \mathrm{l}$ of a $\mathrm{PFS}_{63}-b$-PDMS ${ }_{513}$ unimer solution $\left(10 \mathrm{mg} \mathrm{ml}^{-1}\right.$ in THF) was added dropwise. After addition the stirring was stopped and the mixture aged overnight. The micelle solution was stirred and $40 \mu \mathrm{l}$ of a $\mathbf{B C P}^{\mathbf{P}}$ unimer solution $\left(10 \mathrm{mg} \mathrm{ml}^{-1}\right.$ in THF) was added dropwise. After addition the stirring was stopped and the mixture aged for 1 week. Monodisperse cylindrical micelles were observed by TEM analysis of a drop-cast of the solution $\left(L_{\mathrm{n}}=465 \mathrm{~nm}, L_{\mathrm{w}}=484 \mathrm{~nm}, L_{\mathrm{w}} / L_{\mathrm{n}}=1.04\right)$.

Preparation of monodisperse $\mathbf{B}-\mathbf{A}-\mathbf{B}$ micelles. A is $\mathbf{B C} \mathbf{P}^{\mathbf{P}}$ and $\mathrm{B}$ is PFS- $b$-PDMS In a glove box under an argon atmosphere, $200 \mu \mathbf{~ B C P}^{\mathbf{P}}$ seeds $\left(1 \mathrm{mg} \mathrm{ml}^{-1}\right.$ in EtOAc) were diluted in $2 \mathrm{ml}$ dry and degassed EtOAc. The seed solution was stirred and $200 \mu \mathrm{l}$ of a $\mathbf{B C P}^{\mathbf{P}}$ unimer solution $\left(10 \mathrm{mg} \mathrm{ml}^{-1}\right.$ in THF) was added dropwise. After addition the stirring was stopped and the mixture aged for 1 week. The micelle solution was stirred and $20 \mu \mathrm{l}$ of a $\mathrm{PFS}_{63}-b-\mathrm{PDMS}_{513}$ unimer solution $\left(10 \mathrm{mg} \mathrm{ml}^{-1}\right.$ in THF) was added dropwise. After addition the stirring was stopped and the mixture aged for 1 day. Monodisperse cylindrical micelles were observed by TEM analysis of a drop-cast of the solution $\left(L_{\mathrm{n}}=360 \mathrm{~nm}, L_{\mathrm{w}}=378 \mathrm{~nm}, L_{\mathrm{w}} / L_{\mathrm{n}}=1.05\right)$.

Coordination-driven self-assembly of cylindrical micelles. General procedure using palladium(II) diacetate, $\mathrm{Pd}(\mathrm{OAc})_{2}$. In a glove box under an argon atmosphere, a $0.002 \mathrm{M}$ solution of $\mathrm{Pd}(\mathrm{OAc})_{2}$ in dry and degassed EtOAc $\left(25 \mu \mathrm{l}, 5 \times 10^{-5} \mathrm{mmol}\right.$, 0.5 equiv.) was added to a $0.5 \mathrm{mg} \mathrm{ml}^{-1}$ solution of $\mathbf{B C P}^{\mathbf{P}}$ micelles in dry and degassed EtOAc $\left(100 \mu \mathrm{l}, 2 \times 10^{-4} \mathrm{mmol} \cdot \mathrm{ml}^{-1}-\mathrm{PPh}_{2}\right)$. The red solution was briefly shaken to mix and left to age for $24 \mathrm{~h}$ before analysis by ${ }^{31} \mathrm{P}$ NMR spectroscopy (Supplementary Fig. 5), TEM and EDX (Supplementary Fig. 6). ${ }^{31} \mathrm{P}$ NMR (202 MHz; EtOAc): $\delta 22.6$ (br s, - $\mathrm{PPh}_{2}$ ). The micelles could be diluted with THF, a common solvent for both blocks, without disassembling (Supplementary Fig. 7). Samples of $\mathbf{B C P}^{\mathbf{P}}$ micelles crosslinked with $\mathrm{Pd}(\mathrm{OAc})_{2}$ were not stable indefinitely and aggregation was observed when samples were analysed by TEM after 1 week (Supplementary Fig. 8).

General procedure using tris(dibenzylideneacetone)dipalladium(0) chloroform adduct, $\mathrm{Pd}_{2}(\mathrm{dba})_{3} \cdot \mathrm{CHCl}_{3}$. In a glove box under an argon atmosphere, a $0.002 \mathrm{M}$ solution of $\mathrm{Pd}_{2}(\mathrm{dba})_{3} \cdot \mathrm{CHCl}_{3}$ in dry and degassed EtOAc $\left(25 \mu \mathrm{l}, 5 \times 10^{-5} \mathrm{mmol}\right.$, 0.5 equiv.) was added to a $0.5 \mathrm{mg} \mathrm{ml}^{-1}$ solution of $\mathbf{B C P} \mathbf{P}^{\mathbf{P}}$ micelles in dry and degassed EtOAc $\left(100 \mu \mathrm{l}, 2 \times 10^{-4} \mathrm{mmol} \cdot \mathrm{ml}^{-1}-\mathrm{PPh}_{2}\right)$. The red solution was briefly shaken to mix and left to age for $24 \mathrm{~h}$ analysis by ${ }^{31} \mathrm{P}$ NMR spectroscopy (Supplementary Fig. 5), TEM and EDX (Supplementary Fig. 9). ${ }^{31} \mathrm{P}$ NMR $\left(202 \mathrm{MHz}\right.$; EtOAc): $\delta 22.9\left(\right.$ br s, $\left.-\mathrm{PPh}_{2}\right)$. See Supplementary note 1 for additional comments regarding the coordination-driven self-assembly.

Reversibility of inter- and intramicelle crosslinking. General procedure. In a glove box under an argon atmosphere, a $0.01 \mathrm{M}$ solution of 1,2-bis (diphenylphosphino)ethane (dppe) $\left(100 \mu \mathrm{l}, 1 \times 10^{-3} \mathrm{mmol}, 2\right.$ equiv. with respect to $\mathrm{Pd})$ was added to a solution of $\mathbf{B C P}^{\mathbf{P}}$ micelles $\left(1 \mathrm{ml}, 0.5 \mathrm{mg} \mathrm{ml}^{-1}, 1 \times 10^{-3}\right.$ $\left.\mathrm{mmol}-\mathrm{PPh}_{2}\right)$ crosslinked with $\mathrm{Pd}_{2}(\mathrm{dba})_{3} \cdot \mathrm{CHCl}_{3}\left(25 \mu \mathrm{l}, 5 \times 10^{-5} \mathrm{mmol}\right)$ in dry and degassed EtOAc. The solution turned yellow on addition of dppe, characteristic of the formation of $\mathrm{Pd}(\mathrm{dppe})_{2}$, was shaken to mix and analysed by TEM and ${ }^{31} \mathrm{P}$ NMR (Supplementary Fig. 12). ${ }^{31} \mathrm{P}$ NMR $\left(202 \mathrm{MHz} ; \mathrm{CD}_{2} \mathrm{Cl}_{2}\right): \delta 31.1$ $\left(\mathrm{Pd}(\mathrm{dppe})_{2}\right)$. Notably, although dppe was strongly coordinating enough to remove intermicelle crosslinks, in the case of both $\mathrm{Pd}(\mathrm{II})$ and $\mathrm{Pd}(0)$ broad ${ }^{31} \mathrm{P}$ NMR signals corresponding to Pd coordinated $\mathbf{B C P}^{\mathbf{P}}$ at $30-32$ p.p.m. were still observed (Supplementary Fig. 12). 
Preparation of hairy rod-like superstructures. General procedure. In a glove box under an argon atmosphere, different equivalents of $\mathrm{PFS}_{63}-b-\mathrm{PDMS}_{513}$ unimer $\left(10 \mathrm{mg} \mathrm{ml}^{-1}\right.$ in THF) were added to solutions of coordinated linear fibres of $\mathbf{B C P}^{\mathbf{P}}$ micelles, diluted in dry and degassed EtOAc to maintain the THF percentage at $\sim 10 \%$ (Fig. 4d,e and Supplementary Fig. 25).

Preparation of micelle-based materials. General procedure. In a glove box under an argon atmosphere, a $0.002 \mathrm{M}$ solution of $\mathrm{Pd}_{2}(\mathrm{dba})_{3} \cdot \mathrm{CHCl}_{3}$ in dry and degassed EtOAc $\left(25 \mu \mathrm{l}, 5 \times 10^{-5} \mathrm{mmol}, 0.5\right.$ equiv.) was added to a $1 \mathrm{mg} \mathrm{ml}^{-1}$ solution of BCP ${ }^{\mathbf{P}}$ micelles in dry and degassed EtOAc $\left(100 \mu \mathrm{l}, 2 \times 10^{-4} \mathrm{mmol} \mathrm{ml}^{-1}-\mathrm{PPh}_{2}\right)$. The red solution was briefly shaken to mix and left to age for $24 \mathrm{~h}$, over which time the colour faded to afford a cloudy pale yellow solution. The solution was transferred in air on to a layer of deionized water within a small glass Petri dish in the centre of a larger glass Petri dish. The EtOAc was evaporated with blowing nitrogen to afford a micelle film on the water surface. Deionized water was added slowly to float the film out of the smaller Petri dish where it could be removed from the surface and manipulated in air. The resulting material was analysed by optical microscopy, AFM, SEM and TEM. A sample of the film was dispersed by stirring in $\mathrm{C}_{6} \mathrm{D}_{6}$ and analysed by NMR. ${ }^{31} \mathrm{P}$ NMR $\left(202 \mathrm{MHz} ; \mathrm{C}_{6} \mathrm{D}_{6}\right): \delta 29.9\left(\mathrm{br} \mathrm{s},-\mathrm{PPh}_{2}\right) ;{ }^{1} \mathrm{H}$ NMR (500 MHz; $\left.\mathrm{C}_{6} \mathrm{D}_{6}\right): \delta 0.14-0.41\left(1728 \mathrm{H}\right.$, br m, siloxane $\left.\mathrm{SiCH}_{3}\right), 0.56(135 \mathrm{H}, \mathrm{s}$, $\left.\mathrm{Si}\left(\mathrm{CH}_{3}\right)_{2}\right), 2.50\left(137 \mathrm{H}\right.$, br m, $\left.\mathrm{CH}_{2} \mathrm{P}\right), 4.12(100 \mathrm{H}, \mathrm{s}, \mathrm{CpH}), 4.29(95 \mathrm{H}, \mathrm{s}, \mathrm{CpH})$, 5.87-6.01 (319H, br m, $\left.\mathrm{CHCH}_{2}\right)$ and $6.16\left(156 \mathrm{H}, \mathrm{br} \mathrm{m}, \mathrm{CHCH}_{2}\right)$. Signals corresponding to $\mathrm{SiCH}_{2}$ and the phosphine aryl protons could not be assigned due to peak broadening and overlap with adjacent signals. We hypothesize that the reduced integrals are due to the presence of remaining crosslinks between phosphine moieties that prevent complete dissolution of the material. Theoretical ${ }^{1} \mathrm{H}$ NMR integrals are stated below. DLS confirmed the presence of aggregates in solution (Supplementary Fig. 26). Theoretical ${ }^{1} \mathrm{H}$ NMR (500 MHz; $\mathrm{C}_{6} \mathrm{D}_{6}$ ): $\delta$ 0.21-0.38 (1728H, br m, siloxane $\left.\mathrm{SiCH}_{3}\right), 0.56\left(360 \mathrm{H}, \mathrm{s}, \mathrm{Si}\left(\mathrm{CH}_{3}\right)_{2}\right), 0.89(400 \mathrm{H}$, br m, $\left.\mathrm{SiCH}_{2}\right), 2.29\left(400 \mathrm{H}\right.$, br m, $\left.\mathrm{CH}_{2} \mathrm{P}\right), 4.12(240 \mathrm{H}, \mathrm{s}, \mathrm{CpH}), 4.29(240 \mathrm{H}, \mathrm{s}, \mathrm{CpH})$, 5.90-6.00 $\left(750 \mathrm{H}\right.$, br m, $\left.\mathrm{CHCH}_{2}\right), 6.09-6.26\left(375 \mathrm{H}\right.$, br m, $\left.\mathrm{CHCH}_{2}\right), 7.07-7.17$ $(1200 \mathrm{H}, \mathrm{br} \mathrm{m}, \mathrm{ArH})$ and $7.54-7.57(800 \mathrm{H}, \mathrm{br} \mathrm{m}, \mathrm{ArH})$.

Data availability. The data that support the findings of this study are available from the corresponding authors on request.

\section{References}

1. Zhang, S. Molecular self-assembly: Another brick in the wall. Nat. Nanotechnol. 1, 169-170 (2006).

2. Fratzl, P. \& Weinkamer, R. Nature's hierarchical materials. Prog. Mater. Sci. 52, 1263-1334 (2007).

3. Philp, D. \& Stoddart, J. F. Self-assembly in natural and unnatural systems. Angew. Chem. Int. Ed. 35, 1154-1196 (1996).

4. Studart, A. R. Towards high-performance bioinspired composites. Adv. Mater. 24, 5024-5044 (2012).

5. Fantner, G. E. et al. Sacrificial bonds and hidden length dissipate energy as mineralized fibrils separate during bone fracture. Nat. Mater. 4, 612-616 (2005).

6. Harrington, M. J., Masic, A., Holten-Andersen, N., Waite, J. H. \& Fratzl, P. Iron-clad fibers: a metal-based biological strategy for hard flexible coatings. Science 328, 216-220 (2010).

7. Holten-Andersen, N. et al. pH-induced metal-ligand cross-links inspired by mussel yield self-healing polymer networks with near-covalent elastic moduli. Proc. Natl Acad. Sci. USA 108, 2651-2655 (2011).

8. Yan, X. et al. Supramolecular polymers with tunable topologies via hierarchical coordination-driven self-assembly and hydrogen bonding interfaces. Proc. Natl Acad. Sci. USA 110, 15585-15590 (2013).

9. Whittell, G. R., Hager, M. D., Schubert, U. S. \& Manners, I. Functional soft materials from metallopolymers and metallosupramolecular polymers. Nat. Mater. 10, 176-188 (2011).

10. Burnworth, M. et al. Optically healable supramolecular polymers. Nature 472, 334-337 (2011)

11. Paulusse, J. M. J., Huijbers, J. P. J. \& Sijbesma, R. P. Quantification of ultrasound-induced chain scission in PdII-phosphine coordination polymers. Chem. A Eur. J. 12, 4928-4934 (2006).

12. Yount, W. C., Loveless, D. M. \& Craig, S. L. Small-molecule dynamics and mechanisms underlying the macroscopic mechanical properties of coordinatively cross-linked polymer networks. J. Am. Chem. Soc. 127, 14488-14496 (2005)

13. Wang, F. et al. Metal coordination mediated reversible conversion between linear and cross-linked supramolecular polymers. Angew. Chem. Int. Ed. 49, 1090-1094 (2010)

14. Yan, X. et al. A Multiresponsive, shape-persistent, and elastic supramolecular polymer network gel constructed by orthogonal self-assembly. Adv. Mater. 24, 362-369 (2012).

15. Gorman, C. Metallodendrimers: structural diversity and functional behavior. Adv. Mater. 10, 295-309 (1998).
16. Chase, P. A., Gebbink, R. J. M. K. \& van Koten, G. Where organometallics and dendrimers merge: the incorporation of organometallic species into dendritic molecules. J. Organomet. Chem. 689, 4016-4054 (2004).

17. Northrop, B. H., Yang, H.-B. \& Stang, P. J. Coordination-driven self-assembly of functionalized supramolecular metallacycles. Chem. Commun. 5896-5908 (2008).

18. Chakrabarty, R., Mukherjee, P. S. \& Stang, P. J. Supramolecular coordination: self-assembly of finite two- and three-dimensional ensembles. Chem. Rev. 111, 6810-6918 (2011).

19. Piepenbrock, M.-O. M., Lloyd, G. O., Clarke, N. \& Steed, J. W. Metal- and anion-binding supramolecular gels. Chem. Rev. 110, 1960-2004 (2010).

20. Tam, A. Y.-Y. \& Yam, V. W.-W. Recent advances in metallogels. Chem. Soc. Rev. 42, 1540-1567 (2013).

21. Kim, H.-J., Lee, J.-H. \& Lee, M. Stimuli-responsive gels from reversible coordination polymers. Angew. Chem. Int. Ed. 44, 5810-5814 (2005).

22. Huang, Z. et al. Responsive nematic gels from the self-assembly of aqueous nanofibres. Nat. Commun. 2, 459 (2011).

23. Janiak, C. \& Vieth, J. K. MOFs, MILs and more: concepts, properties and applications for porous coordination networks (PCNs). New J. Chem. 34, 2366-2388 (2010).

24. Cook, T. R., Zheng, Y.-R. \& Stang, P. J. Metal-organic frameworks and selfassembled supramolecular coordination complexes: comparing and contrasting the design, synthesis, and functionality of metal-organic materials. Chem. Rev. 113, 734-777 (2013).

25. Salgado, E. N., Radford, R. J. \& Tezcan, F. A. Metal-directed protein self-assembly. Acc. Chem. Res. 43, 661-672 (2010).

26. Pires, M. M. \& Chmielewski, J. Self-assembly of collagen peptides into microflorettes via metal coordination. J. Am. Chem. Soc. 131, 2706-2712 (2009).

27. Bannwarth, M. B., Weidner, T., Eidmann, E., Landfester, K. \& Crespy, D. Reversible redox-responsive assembly/disassembly of nanoparticles mediated by metal complex formation. Chem. Mater. 26, 1300-1302 (2014).

28. Wang, Y. et al. Patchy particle self-assembly via metal coordination. J. Am. Chem. Soc. 135, 14064-14067 (2013).

29. Glotzer, S. C. \& Solomon, M. J. Anisotropy of building blocks and their assembly into complex structures. Nat. Mater. 6, 557-562 (2007).

30. Quan, Z. \& Fang, J. Superlattices with non-spherical building blocks. Nano Today 5, 390-411 (2010).

31. Blanazs, A., Armes, S. P. \& Ryan, A. J. Self-assembled block copolymer aggregates: from micelles to vesicles and their biological applications. Macromol. Rapid Commun. 30, 267-277 (2009).

32. Mai, Y. \& Eisenberg, A. Self-assembly of block copolymers. Chem. Soc. Rev. 41, 5969-5985 (2012).

33. Hayward, R. C. \& Pochan, D. J. Tailored assemblies of block copolymers in solution: it is all about the process. Macromolecules 43, 3577-3584 (2010).

34. Moughton, A. O., Hillmyer, M. A. \& Lodge, T. P. Multicompartment block polymer micelles. Macromolecules 45, 2-19 (2012).

35. Smart, T. et al. Block copolymer nanostructures. Nano Today 3, 38-46 (2008)

36. Gröschel, A. H. et al. Precise hierarchical self-assembly of multicompartment micelles. Nat. Commun. 3, 710 (2012).

37. Gröschel, A. H. et al. Guided hierarchical co-assembly of soft patchy nanoparticles. Nature 503, 247-251 (2013).

38. Wang, X. et al. Cylindrical block copolymer micelles and co-micelles of controlled length and architecture. Science 317, 644-647 (2007).

39. Schmelz, J., Schacher, F. H. \& Schmalz, H. Cylindrical crystalline-core micelles: pushing the limits of solution self-assembly. Soft Matter 9, 2101-2107 (2013).

40. Hudson, Z. M., Lunn, D. J., Winnik, M. A. \& Manners, I. Colour-tunable fluorescent multiblock micelles. Nat. Commun. 5, 3372 (2014).

41. Gilroy, J. B. et al. Monodisperse cylindrical micelles by crystallization-driven living self-assembly. Nat. Chem. 2, 566-570 (2010).

42. Rupar, P. A., Chabanne, L., Winnik, M. A. \& Manners, I. Non-centrosymmetric cylindrical micelles by unidirectional growth. Science 337, 559-562 (2012).

43. Qiu, H. et al. Tunable supermicelle architectures from the hierarchical self-assembly of amphiphilic cylindrical B-A-B triblock co-micelles. Angew. Chem. Int. Ed. 51, 11882-11885 (2012).

44. Qiu, H., Hudson, Z. M., Winnik, M. A. \& Manners, I. Multidimensional hierarchical self-assembly of amphiphilic cylindrical block comicelles. Science 347, 1329-1332 (2015).

45. Mohd Yusoff, S. F., Gilroy, J. B., Cambridge, G., Winnik, M. A. \& Manners, I. End-to-end coupling and network formation behavior of cylindrical block copolymer micelles with a crystalline polyferrocenylsilane core. J. Am. Chem. Soc. 133, 11220-11230 (2011).

46. Lunn, D. J., Finnegan, J. R. \& Manners, I. Self-assembly of 'patchy' nanoparticles: a versatile approach to functional hierarchical materials. Chem. Sci. 6, 3663-3673 (2015).

47. Yan, X., Liu, G. \& Li, Z. Preparation and phase segregation of block copolymer nanotube multiblocks. J. Am. Chem. Soc. 126, 10059-10066 (2004). 
48. Li, X., Liu, G. \& Han, D. Wrapping amino-bearing block copolymer cylinders around carboxyl-bearing nanofibers: a case of hierarchical assembly. Soft Matter 7, 8216-8223 (2011).

49. Amatore, C., Carré, E., Jutand, A. \& M'Barki, M. A. Rates and mechanism of the formation of zerovalent palladium complexes from mixtures of $\mathrm{Pd}(\mathrm{OAc})_{2}$ and tertiary phosphines and their reactivity in oxidative additions. Organometallics 14, 1818-1826 (1995).

50. Amatore, C. \& Jutand, A. Role of dba in the reactivity of palladium $(0)$ complexes generated in situ from mixtures of $\mathrm{Pd}(\mathrm{dba})_{2}$ and phosphines. Coord. Chem. Rev. 178-180, 511-528 (1998).

51. Poyraz, A. S., Kuo, C.-H., Biswas, S., King'ondu, C. K. \& Suib, S. L. A general approach to crystalline and monomodal pore size mesoporous materials. Nat. Commun. 4, 2952 (2013).

52. Gao, F., Lian, C., Zhou, L., Liu, H. \& Hu, J. Phase separation of mixed micelles and synthesis of hierarchical porous materials. Langmuir 30, 11284-11291 (2014).

53. Abetz, V., Spontak, R. J. \& Talmon, Y. in Macromolecular Engineering: Precise Synthesis, Materials Properties, Applications, Vol. 3 (eds Matyjaszewski, K., Gnanou, Y. \& Leibler, L.) 1649-1685 (Wiley-VCH, Weinheim, 2007).

54. Jinnai, H., Spontak, R. J. \& Nishi, T. Transmission electron microtomography and polymer nanostructures. Macromolecules 43, 1675-1688 (2010).

55. Hailes, R. L. N., Oliver, A. M., Gwyther, J., Whittell, G. R. \& Manners, I. Polyferrocenylsilanes: synthesis, properties, and applications. Chem. Soc. Rev doi:10.1039/c6cs00155f (2016).

56. Zalesskiy, S. S. \& Ananikov, V. P. $\mathrm{Pd}_{2}(\mathrm{dba})_{3}$ as a precursor of soluble metal complexes and nanoparticles: determination of palladium active species for catalysis and synthesis. Organometallics 31, 2302-2309 (2012).

57. Mott, P. H. \& Roland, C. M. Limits to Poisson's ratio in isotropic materials. Phys. Rev. B 80, 132104 (2009).

58. Zheng, Q. S., Braunfeld, M. B., Sedat, J. W. \& Agard, D. A. An improved strategy for automated electron microscopic tomography. J. Struct. Biol. 147, 91-101 (2004).

59. Crowther, R. A., DeRosier, D. J. \& Klug, A. The reconstruction of a threedimensional structure from projections and its application to electron microscopy. Proc. R. Soc. A Math. Phys. Eng. Sci. 317, 319-340 (1970).

\section{Acknowledgements}

D.J.L. thanks the Bristol Chemical Synthesis Centre for Doctoral Training, funded by EPSRC (EP/G036764/1), for the provision of a PhD studentship and the ERC for continued financial support. O.E.C.G. notes his affiliation with the Bristol Centre for
Functional Nanomaterials. D.P.A. is grateful for financial support from BD Technologies, and K.P.M. and R.J.S. thank the NC State Nonwovens Institute and Mann + Hummel for financial support. This work was performed in part at the North Carolina State University Analytical Instrumentation Facility (AIF), which is supported by the State of North Carolina and the National Science Foundation (ECCS-1542015). The AIF is a member of the North Carolina Research Triangle Nanotechnology Network (RTNN), a site in the National Nanotechnology Coordinated Infrastructure (NNCI). M.A.W. thanks the Natural Sciences and Engineering Research Council (NSERC) of Canada for financial support. I.M. thanks the EU for an ERC Advanced Investigator Grant.

\section{Author contributions}

D.J.L., P.G.P. and I.M. devised the project; D.J.L. carried out the experiments; O.E.C.G. carried out the optical microscopy, SEM and AFM analysis; D.P.A. conducted the nanoindentation and low-voltage SEM analyses; R.J.S. and K.P.M. performed TEMT; D.J.L. and I.M. wrote the manuscript with input from the other co-authors. The project was supervised by I.M. and P.G.P. with input from G.R.W.

\section{Additional information}

Supplementary Information accompanies this paper at http://www.nature.com/ naturecommunications

Competing financial interests: The authors declare no competing financial interests.

Reprints and permission information is available online at http://npg.nature.com/ reprintsandpermissions/

How to cite this article: Lunn, D. J. et al. Microfibres and macroscopic films from the coordination-driven hierarchical self-assembly of cylindrical micelles. Nat. Commun. 7:12371 doi: 10.1038/ncomms12371 (2016).

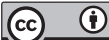

This work is licensed under a Creative Commons Attribution 4.0 International License. The images or other third party material in this article are included in the article's Creative Commons license, unless indicated otherwise in the credit line; if the material is not included under the Creative Commons license, users will need to obtain permission from the license holder to reproduce the material. To view a copy of this license, visit http://creativecommons.org/licenses/by/4.0/

(C) The Author(s) 2016 